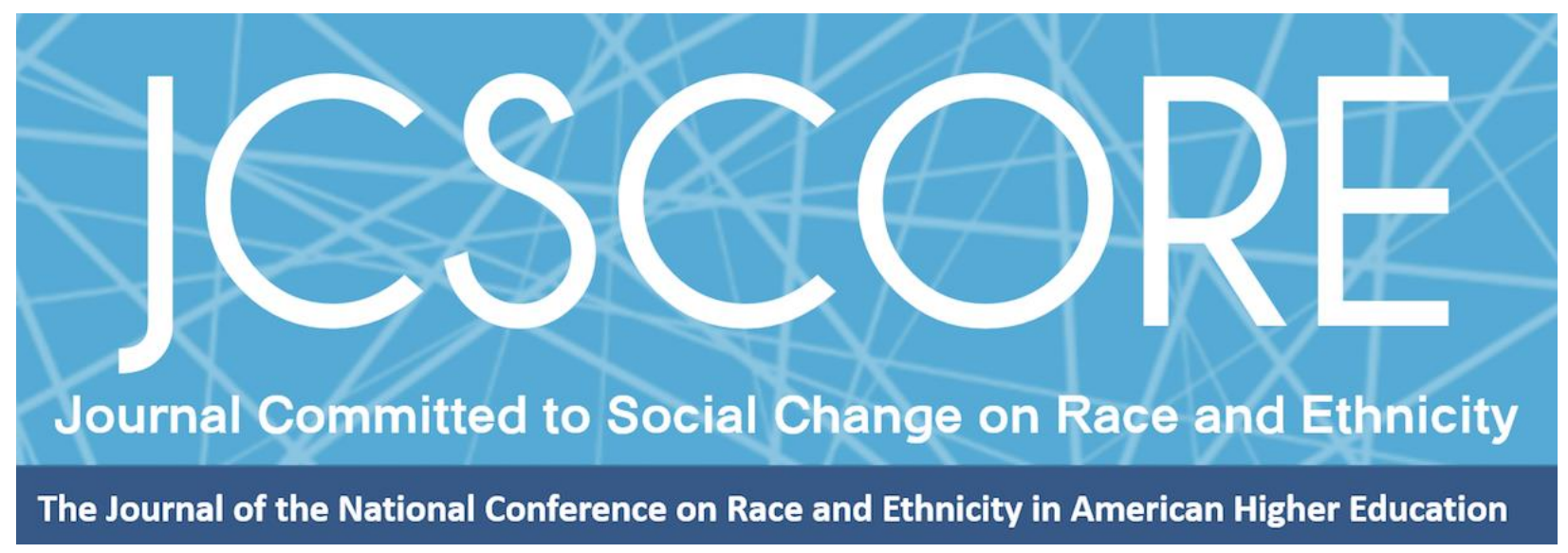

\title{
INSIGHTS INTO THE SENSE OF BELONGING FROM WOMEN OF COLOR: INTERCONNECTIONS OF CULTURAL COMPETENCE, EXPECTATIONS, INSTITUTIONAL DIVERSITY, AND COUNTERSPACES
}

\author{
Annemarie Vaccaro \\ University of Rhode Island 1 \\ Holly J. Swanson 1 \\ Melissa Ann Marcotte \\ Rhode Island College \\ Barbara M. Newman 1
}

Journal Committed to Social Change on Race and Ethnicity Volume 5, Issue 2 | 2019

Copyright (C) 2019 Board of Regents of The University of Oklahoma on behalf of the Southwest Center for Human Relations Studies.

Permission of the Publisher is required for resale or distribution and for all derivative works, including compilations and translations. Quoting small sections of text is allowed as long as there is appropriate attribution. 


\title{
Insights into the Sense of Belonging from Women of Color: Interconnections of Cultural Competence, Expectations, Institutional Diversity, and Counterspaces
}

\author{
Annemarie Vaccaro \\ University of Rhode Island 1 \\ Holly J. Swanson 1 \\ Melissa Ann Marcotte \\ Rhode Island College \\ Barbara M. Newman 1
}

\begin{abstract}
Belonging has been described as a basic human need (Strayhorn, 2012) associated with academic success. Yet, research suggests that students from minoritized social identity groups report a lower sense of belonging than their privileged peers. Data collected via a grounded theory study offer qualitative insight into the development of belonging for Women of Color during their first semester at a predominately white university. In this paper, we use the term Women of Color, as described by Mohanty (1991) to refer to the "sociopolitical designation for [women] of African, Caribbean, Asian and Latin American descent, and Native peoples of the U.S. [and]... new immigrants to the U.S." (p. 7). Rich student narratives reveal previously undocumented interconnections among the development of a sense of belonging, cultural competency, unmet expectations, lack of compositional and structural diversity, and campus counterspaces.
\end{abstract}

Belonging has been described as a basic human need (Strayhorn, 2012) associated with academic success. Yet, research suggests the development of belonging can be challenging for students from minoritized social identity groups because they experience overt and subtle exclusion (Hurtado \& Carter, 1997; Johnson et al., 2007; Strayhorn, 2012; Vaccaro \& Newman, 2016, 2017). Using rich data collected from Women of Color via a grounded theory study, this paper explores previously undocumented interconnections among belonging, cultural competency, 
Journal Committed to Social Change on Race and Ethnicity | Volume 5, Issue 2 | 2019

unmet expectations, lack of compositional and structural diversity, and campus counterspaces.

\section{Sensitizing Literature Constructs}

Constructivist grounded theory is a qualitative methodology rooted in inductive and iterative processes. It is used by scholars to draw conclusions (and sometimes construct theory) based upon concepts that emerge from data collection. As such, starting a study with particular theory in mind—or a literature review that points to a particular gap needing illumination—is discouraged (Charmaz, 2019). Instead, grounded theorists review specific literature (i.e., sensitizing constructs) related to emergent categories (Charmaz, 2014) as the study progresses. Interconnections among belonging, counterspaces, cultural competency, and compositional and structural diversity emerged as important grounded theory categories in this project. Therefore, we reviewed writings about those constructs and provide a very brief overview here.

\section{Belonging and Campus Counterspaces}

Having a sense of belonging can be described as feeling included and accepted by a group with which one has some sort of common or shared experience. Strayhorn argued that, for college students, developing belonging in the larger college community is a "basic human need and fundamental motivation that drives student behaviors, and facilitates educational success" (Strayhorn, 2012, p. 87). Belonging has been associated with important educational outcomes including academic success (Freeman, Anderman, \& Jensen, 2007; Strayhorn, 2008, 2012), persistence (Hausmann, Schofield, \& Woods, 2007; Hoffman, Richmond, Marrow, \& Salomone, 2002/2003), and 
Journal Committed to Social Change on Race and Ethnicity | Volume 5, Issue 2 | 2019

psychological adjustment (Pittman \& Richmond, 2008). Research also suggests that belonging development may be unique for students from minoritized social identity backgrounds including first-generation students (Blaney \& Stout, 2017; Means \& Pyne, 2017; Stebleton, Soria, \& Huesman, 2014) and Students of Color (Hausmann et al., 2007; Hurtado \& Carter, 1997; Johnson et al., 2007; Nuñez, 2009; Strayhorn, 2012).

Stephens, Fryberg, Markus, and Johnson (2012) argued that Students of Color can feel "a chronic state of belonging uncertainty" (p. 1191). Empirical research has confirmed that Students of Color report lower levels of belonging than White peers (Hurtado \& Carter, 1997; Johnson et al., 2007; Strayhorn, 2008). Only one study contradicts this conclusion about lower senses of belonging for Students of Color. Using data from 4,471 students, Locks, Hurtado, Bowman, and Oseguera (2008) found no main effect differences in the belonging experiences of White students and Students of Color. They did, however, note an indirect effect that "women of color were slightly more likely than men to have a higher sense of belonging in college" (Locks et al., 2008, p. 277). Beyond this one mention of a small indirect effect in the Locks et al. study, we know little about if, and how, the belonging development process might be unique for Women of Color as they transition into their first year of college.

Factors that can contribute to a lack of a sense of belonging for Students of Color include unwelcoming campus climates (Hurtado \& Carter, 1997; Johnson et al., 2007; Locks et al., 2008; Nuñez, 2009; Strayhorn, 2012) and negative interactions with white peers (Locks et al., 2008; Maramba \& Museus, 2012/13; Nuñez, 2009). Conversely, positive cross-cultural interactions supported belonging for Filipino American students (Maramba \& Museus, 2012/13) while extracurricular involvement fostered belonging for 
Journal Committed to Social Change on Race and Ethnicity | Volume 5, Issue 2 | 2019

Black men (Strayhorn, 2012) and Latino/a students (Hurtado \& Carter, 1997). We surmise that some of the campus involvement noted in these aforementioned studies could be due to the psychosocial contribution of counterspaces. Campus counterspaces are micro-environments where Students of Color can develop a sense of belonging in otherwise hostile, predominately white institutions (PWI) (Pérez Huber \& Cueva, 2012; Vaccaro \& Camba-Kelsay, 2016). Yosso, Smith, Ceja, and Solórzano (2009) characterized counterspaces as places where students sharing similar social identities can "vent frustrations and cultivate friendships with people who share many of their experiences" (Yosso et al., 2009, p. 677). Other scholars have described counterspaces as "ethnic enclaves that offer shelter from the psycho-emotional harms of racial microaggressions" (Harper \& Hurtado, 2007, p. 14). Vaccaro and Camba-Kelsay (2016) found Women of Color experienced counterspaces as important sites to build support networks, develop a sense of belonging, and find reprieve (i.e., a getaway) from the otherwise oppressive campus environment.

\section{Institutional Diversity and Cultural Competency}

Scholars have long noted the importance of structural diversity in higher education. Compositional diversity (i.e., a proportional representation of racial and ethnic groups) can be one facet of structural diversity. However, the complex process of creating inclusive campus environments can include many additional strategies such as offering diversity curricula, creating venues for intergroup dialogues/interactions, and providing multicultural offices/programs/services on campus (Hurtado, ClaytonPederson, Allen, \& Milem, 1998; Williams, 2013). Higher education scholars have argued that single pronged efforts, such as increasing enrollment of diverse students, 
Journal Committed to Social Change on Race and Ethnicity | Volume 5, Issue 2 | 2019

are insufficient for improving climate or fostering equity (Hurtado et al., 1998; Milem, Chang, \& antonio, 2005; Williams, 2013). Instead, higher education institutions must pair multi-pronged structural diversity efforts 'in intentional ways that enhance students' intercultural competency, cognitive complexity, and ability to work in diverse groups" (Milem et al., 2005, p. v). Still, for many Students of Color, compositional diversity is often the most salient feature lacking in PWIs. Vaccaro and Camba-Kelsay (2016) discussed how this under-representation acts as an environmental microaggression that can foster the feeling of exclusion because it "perpetuates the idea that people of color do not belong" (p. 51) in institutions of higher education. Therefore, while compositional diversity is not the only dimension of campus climate that needs to be addressed (Milem et al., 2005), it can be an extraordinarily impactful first step to facilitating a sense of belonging in Students of Color.

Although much writing extolls the importance of diversity requirements in college curricula (Gurin, Dey, Hurtado, \& Gurin, 2002; Williams, Berger, \& McClendon, 2005), we know little about undergraduate student perceptions of their own cultural competence, the competency of their peers, or how those perceptions relate to the development of belonging on campus. There is evidence that important educational outcomes (e.g., civic, educational; Gurin et al., 2002) and belonging (Locks et al., 2008) are enhanced by extensive informal interracial interactions. Yet, Locks et al. (2008) noted that this interaction must be "frequent" and "positive" (p. 272) to have a positive effect on belonging.

Cultural competency, humility, and desire. The literature on cultural competency and cultural humility adds insight into the ways Students of Color respond 
Journal Committed to Social Change on Race and Ethnicity | Volume 5, Issue 2 | 2019

to compositional and structural diversity and develop their sense of belonging as they transition to a university. Definitions of what it means to be culturally competent vary depending on the discipline and/or organizational context (Camphina-Bacote, 2002; Pope \& Reynolds, 1997; Pope, Reynolds, \& Mueller, 2004, 2019; Sue, 2001). However, most models contain three consistent components: awareness, knowledge and skills. Tervalon and Murray-García (1998) introduced an alternative term, cultural humility, a dynamic, on-going process wherein students are open and eager to learn about other cultures; self-reflective in their own position; humble enough to be self-critical; and seek out information when they do not know the answer. In higher education, Pope, Reynolds, and Mueller (2019) re-defined cultural competency to include the importance of humility and social justice action. Their model also responds to critiques that the term cultural competency suggests a finite or achievable goal and excludes facets of cultural humility. Cultural competency is thus viewed as an ongoing process whereby individuals:

consistently challenge themselves to increase their awareness and knowledge of self, of others, and of the relationship between the two; understanding systems of oppression and inequities to create a deeper understanding of structural barriers within higher education; and develop the advocacy and action skills essential to eradicating the structural barriers, eliminate inequalities, and create multicultural change on campus and in society. (Pope et al., 2019, p. 6)

Camphina-Bacote (2002) argued that awareness, knowledge, and skills are very important, but they are not sufficient. Her cultural competency model contains two additional components—cultural desire and cultural encounters. Expanding on Tervalon and Murray-García's (1998) work on cultural humility, Camphina-Bacote (2002) contended that cultural competency requires cultural desire-which is "a genuine passion to be open and flexible with others, to accept differences and build on 
Journal Committed to Social Change on Race and Ethnicity | Volume 5, Issue 2 | 2019

similarities, and to be willing to learn from others" (p. 183). Those with cultural desire want to increase their cultural competency not because they are required to do so, but because they possess a genuine interest in learning to think and act more inclusively. The other aspect of Camphina-Bacote's (2002) model that sets it apart from others is the aspect of cultural encounters. Camphia-Bacote (2002) argued that gaining awareness, knowledge, and skills via educational interventions (e.g., reading, classroom learning, diversity training) are insufficient. To become truly competent, individuals must have significant and sustained cross-cultural interactions-or cultural encounters—with individuals from diverse backgrounds.

\section{Methods}

For this study, we adopted a constructivist grounded theory approach that closely aligns with social constructivist views that "stress social contexts, interaction, sharing viewpoints, and interpretive understandings ... [and purport] knowing and learning [are] embedded in social life" (Charmaz, 2014, p. 14). Our social constructivist views are also shaped by our positionality as diverse cisgender women scholars whose teaching, practice, and scholarship acknowledges the socio-political realities of inequality embedded in social structures-which can influence students' lives in profound ways.

This constructivist grounded theory (Charmaz, 2014) study sought to answer the following research question: How do students define, develop, and make meaning of a sense of belonging over the course of the first year of college? A previously published model offers our broad conceptual findings about the development of belonging for 51 diverse participants (Vaccaro \& Newman, 2016). Constructivist grounded theory methodology (Charmaz, 2014) values emergent categories co-constructed with 
Journal Committed to Social Change on Race and Ethnicity | Volume 5, Issue 2 | 2019

participants. Through our grounded theory analytic process, we examined our data by sub-groups of participants and found additional and nuanced information about the development of belonging for Women of Color. These emergent categories, summarized in this paper, were not expressed by any of the other 43 participantsincluding White women or Men of Color.

\section{Data Collection}

Using grounded theory purposive sampling, we recruited first year students at a mid-sized, public research university in order to co-construct rich understandings of belonging development during the first year of college. Emails and flyers were sent to first year advising offices, residence halls, and multicultural centers. A total of 51 diverse first year students participated in the study. Table 1 provides basic demographics of the sub-sample of eight cisgender Women of Color about whom this paper focuses.

Table 1. Study Participants

\begin{tabular}{|c|c|c|}
\hline Pseudonym & $\begin{array}{c}\text { Self-Described } \\
\text { Race/Ethnicity }\end{array}$ & Major \\
\hline Delores & Latina & Nursing \\
\hline Lizette & $\begin{array}{c}\text { Multiracial/Cape Verdean, } \\
\text { Latina, African }\end{array}$ & Undeclared \\
\hline Destiny & Black/Native American & Undeclared \\
\hline Kendra & Black & $\begin{array}{c}\text { Commications/Political } \\
\text { Science }\end{array}$ \\
\hline Valerie & Multiracial & $\begin{array}{c}\text { Public } \\
\text { Relations/Communications }\end{array}$ \\
\hline Camila & Biracial (Latina/White) & Political Science \\
\hline Hoa & Asian American/Vietnamese & Engineering \\
\hline Lisa & Asian American/Chinese & Psychology \\
\hline
\end{tabular}

Data were collected through two semi-structured, individual interviews over the course of the first year of college. Protocol questions included "How do you define 
Journal Committed to Social Change on Race and Ethnicity | Volume 5, Issue 2 | 2019

belonging? Were there any experiences or people especially important in influencing your sense of belonging-positively or negatively?" When students arrived for their interviews, we invited them to complete a demographic form. Using this form, we asked tailored questions about belonging related to their social identities. For instance, we asked "On your demographic form, you identified as a [Latina, Black woman, Asian woman]. Can you give me some examples of what it is like to be a [Latina, Black woman, Asian woman] on campus?" and "How do your identities influence your sense of belonging?" We kept memos regarding our interpretations. Our analytic process drew upon initial and focused coding strategies (Charmaz, 2014). The focused coding process yielded eight broad categories under which all open codes fell. This paper reports selected results from emergent categories about belonging, cultural competency, unmet expectations, counterspaces, and compositional and structural diversity from our sub-sample of Women of Color.

\section{Trustworthiness and Credibility}

We used a variety of strategies to ensure trustworthiness and credibility (Jones, Torres, \& Arminio, 2014). First, we triangulated data from our memos and both interviews. Second, we engaged in analytic triangulation where members of our research team conducted independent open coding and then compared their open codes with at least two other researchers. As a team, we then developed and applied only the focused codes $100 \%$ of the team agreed upon. Third, discrepant case analysis was used to ensure that our conclusions were applicable to the sub-sample of eight Women of Color (and not the other 43 participants). Fourth, member checking was used so that our interpretations aligned with participant meaning-making. Fifth, the research 
Journal Committed to Social Change on Race and Ethnicity | Volume 5, Issue 2 | 2019

team constantly reflected upon relational competence (Jones et al., 2014). We discussed our power and positionality as a research team of eight cisgender women who were diverse in ages, religions, races, ethnicities, and social classes. Sixth, we attempted to build trust with participants by having the same interviewer conduct both interviews and by paying attention to complex insider-outsider statuses of gender and race (Jones et al., 2014). Thirteen of the sixteen interviews with this sub-sample were conducted by members of the research team who self-identified as students (graduatelevel) and Women of Color themselves.

\section{Limitations}

This belonging study did not use an explicit intersectional framework. Thus, we cannot know if, or how exactly, race and gender intersected to shape these findings. However, we can confidently say that none of the other 43 participants (including White women and Men of Color) talked about belonging in the context of cultural competency, unmet expectations, compositional and structural diversity, and counterspaces. Another limitation is that our data do not illuminate how emergent categories (cultural competency, unmet expectations, compositional and structural diversity, counterspaces) interact with one another to influence belonging. Such explorations are ideal for future studies. We can only report that women's prose suggest a complex interweaving of these categories. Future research is needed to determine if these findings are transferrable to other Women of Color and/or minoritized populations at other PWIs. Our findings are limited to eight women of color from one campus; their experiences, and perspectives certainly do not represent all Women of Color. 
Journal Committed to Social Change on Race and Ethnicity | Volume 5, Issue 2 | 2019

\section{Findings}

Charmaz (2014) noted that a strong grounded theory findings section "takes the reader into a story" (p. 314) contains "enough details for providing the context and the setting," (p. 316) and weaves together "interpretation and empirical evidence" (p. 287). As such, we interweave student quotes with literature for a robust grounded theory depiction of five emergent categories. Our participants did not use the term cultural competency, but we do so throughout the findings to draw attention to the connection between our data and prior literature. It is important to note that students used their own terms, but talked extensively about key facets of cultural competency (e.g., knowledge, skills, encounters, desire, humility) found in the literature (Camphina-Bacote, 2002; Pope \& Reynolds, 1997; Pope, Reynolds, \& Mueller, 2004, 2019; Sue, 2001; Tervalon and Murray-García, 1998). We draw attention to these distinct facets of cultural competency as described by participants in the context of their belonging narratives.

"In high school...minorities were the majority...and here people aren't educated" In this section, we hear women address the interconnections of cultural competence (or lack thereof), compositional and structural diversity, and belonging. They described vast differences between their feelings of belonging in their home communities as compared to the PWI. These comments were often contextualized by descriptions about the ways the university was not as racially or ethnically diverse as their homes, neighborhoods, or K-12 schools. For instance, Delores grew up in "very diverse communities [with] people from everywhere, white and black, everywhere. So that's how l've been for all these years. But here it's less like, it's more of just ... white people." 
Journal Committed to Social Change on Race and Ethnicity | Volume 5, Issue 2 | 2019

Participants viewed their prior experiences with diverse communities as an asset—one that many of their white peers lacked. For instance, Kendra compared her pre-college experiences—which fostered her own cultural competency-to those of her white peers. She suggests that because her white peers were not exposed to diverse pre-college environments, they did not have the opportunity for cultural encounters (Camphina-Bacote, 2002) and, thus, did not develop basic cultural competency (i.e., awareness or knowledge about People of Color).

I was telling her (my white roommate) that my high school was really diverse, it had all these people. And she was telling me, "My high school was not like that." And, I was like, "Did you have Black people in your town or [Latinx] people?" And, she's like: "Not really, I only know" - and I thought this was interesting-"I only know Black people from movies." That's how she knows them! . . I feel like when I say [white peers are] ignorant to my friends, they think I'm saying stupid. But, it's not stupid; it's just that people don't know. A lot of these kids just don't know. I know more than just about (my culture) Cape Verde. I know about Columbians, I know about Mexicans, I even know about Chinese because I had a lot of friends who were Chinese at my high school. And, not even just that...my best friend is gay. I just know a lot and I feel like I wanted them to know. . . They (white peers) weren't exposed, you can tell ... people aren't educated.

Kendra felt she had far greater cultural competency (i.e., awareness, knowledge, encounters) than her white peers, which she gleaned prior to arrival at college. Kendra went on to explain:

[In high school] we would call each other out on it (discrimination). I just feel that people in my high school were more real...more open. Here, it's just so fake to me. The way that [white] people talk to each other and treat each other. I don't know, it's just weird for me.

In high school, Kendra developed cultural competency (e.g., awareness, knowledge) to recognize stereotypes and honed the cultural competency skill to advocate on behalf of social justice (Pope et al., 2019) and challenge her peers. She compared her ability to 
Journal Committed to Social Change on Race and Ethnicity | Volume 5, Issue 2 | 2019

effectively challenge bias with what she perceived as fakeness or a lack of cultural competency on the part of her white peers.

Participants, like Kendra, recognized cultural competency as an asset that they could use to navigate the PWI. Most referenced building cultural competency via cultural encounters (Camphina-Bacote, 2002) in diverse K-12 and community settings where they gained cultural awareness and knowledge of people from other cultural backgrounds. Valerie shared:

I was used to [diversity] in high school . . . there were a lot of minorities-well minorities were the majority_basically ... Coming here I was like-I feel like I was in a different country . . . because I wasn't used to it. I felt like I was a minority and I felt like every time I would walk, someone would stare at me and be like: "Oh, she's a different race, she's a different color." ... So, it's kind of hard to get used to that since I was used to like everyday walking in the hallways at high school, l'd see like different colors, l'd see different races. So, it's like easy for me back at home because I was used to it . . . Belonging to me means fitting in [but,] coming here, I was just like in a corner to myself.

Valerie explained how the initial shock of being one of the few Women of Color on campus, being "by myself," and not "fitting in" negatively influenced her development of a sense of belonging during the first few weeks of school. In this quote, Valerie notes how the compositional diversity "back home" made it "easy" to fit in and feel a sense of belonging.

\section{"This is not what we thought it would be"}

Students explained how their sense of belonging was diminished when their expectations for a diverse learning environment (i.e., structural and compositional diversity) on campus went unfulfilled. Women of Color came to this PWI with expectations of a racially diverse environment where their cultural heritage would be valued, and diversity dialogues would be the norm. Where did these expectations come 
Journal Committed to Social Change on Race and Ethnicity | Volume 5, Issue 2 | 2019

from? Many participants assumed that their diverse high school settings were the norm for most educational settings_-including the university. Valerie explained "In high school since we had so many different countries represented ... And, then, coming here, like I thought it would kind of be the same." She was sorely disappointed by the lack of racial diversity upon arrival to campus. Kendra expressed similar sentiments.

I went to my classes and I noticed that I would be [the only person of color]; there wasn't that many minorities. So, OK, whatever, I had to get used to that. But, I kept telling my friends [from high school]: "Guys, this is not what we thought it would be."

Student expectations for a diverse learning environment were also shaped by university messaging and programs. The university promoted itself as a diverse campus via admission materials by showing photos of diverse students on campus and orientation processes (e.g., tours, programming). Hoa explained: "summer orientation was two days and one night and we had a tour going around [the university which included a stop at] the Multicultural Center [where the guides] talked about how they accept us for whoever we are." Valerie also felt duped by the orientation process: "When I went for my orientation, there was just a lot of minorities which was good for me because I was used to that." Yet, when the fall semester began and she was surrounded by white peers, she was frustrated that the institution's espoused values regarding diversity were not enacted.

Student expectations of a diverse campus (i.e., compositional diversity) were also fostered through participation in summer bridge programs for first generation students and Students of Color. In those pre-college summer programs, Women of Color were surrounded by racially diverse peers, faculty, and staff. Delores described the program as: 
Journal Committed to Social Change on Race and Ethnicity | Volume 5, Issue 2 | 2019

All mixed [racially]. It's a big group ... we're all different types of people, and we all connect and stuff ... and just feel like we belong ... And that's why I was like, "Oh, I want to come here."

Yet, when she arrived back at the PWI in the fall and was one of the few Women of Color, her expectations of racial diversity and belonging with diverse others went unmet. Such unfulfilled university promises and unmet expectations also led participants to ruminate on their desire for more diversity on campus and the ways the lack of compositional diversity influenced their belonging.

\section{"I wish there was more diversity in this school"}

Participants often referenced a lack of compositional and structural diversity when discussing their campus belonging experiences. They encouraged the university to diversify enrollment, which they believed, would in turn foster the development of cultural competency in themselves and their peers. Kendra called upon the university to enact structural efforts to diversify campus, develop diversity programs, and foster dialogue among diverse students.

I wish there was more diversity in this school ... more diverse students, professors, everything. And, I hope that a lot of kids that don't know about different cultures get to know about different cultures. I just wish there was a way that we could all talk ... [There] needs to be open discussion, learning about different cultures, asking questions.

Kendra notes how important it is for students to have cultural encounters (CamphinaBacote, 2002) with diverse peers. She believed that only through such interactional diversity (Gurin et al., 2002), would students have an opportunity to truly increase their cultural competency. 
Journal Committed to Social Change on Race and Ethnicity | Volume 5, Issue 2 | 2019

Valerie discussed the need for institutional programs and curricula to teach cultural competency for all students-including herself and white peers. These structural diversity initiatives were tied to her sense of belonging at the PWI.

I still wish there were more ... just different races, because I feel that it would give me a better sense of like belonging. Even though I feel like I do belong, I feel like I would be even more comfortable if there were more diversities represented ... Also [I would like to see an] open forum or something for talking about multicultural organizations [and] also people's backgrounds.

Valerie's quote exemplifies how her sense of belonging was intricately tied to the lack of diverse students (e.g., compositional diversity) and diversity initiatives (e.g., structural diversity) on campus. Specifically, she noted how her belonging might increase if the university made both compositional and structural efforts (diverse enrollments, diversity programs) to foster cultural competency among all students on campus.

\section{"People aren't willing to try to get to know somebody else"}

Participants noted how white peers not only lacked cultural competency, but in many cases did not "care" enough to want to learn more. In effect, they lacked the eagerness or cultural desire to learn—which are essential to cultural competency components of humility (Pope et al., 2019; Tervalon \& Murray-García, 1998) and desire (Camphina-Bacote, 2002). Living and learning with white students who showed no cultural humility, or desire to learn, served as a barrier to the development of belonging for Women of Color on campus. For example, Kendra was eager to learn about other people and cultures. At first, she felt that the university Diversity Week was a beneficial structural effort designed to foster cultural competency. However, Diversity Week became a point of frustration when she witnessed white students resist the learning opportunity: 
Journal Committed to Social Change on Race and Ethnicity | Volume 5, Issue 2 | 2019

Diversity Week was a joke to me. Because I feel that kids have to go, and they don't want to-because I would hear them say they don't want to-and then when they were there, they would ... leave or they'd be texting the whole time ... I felt like people didn't care anyways. Because they were forced to be there.

In Kendra's opinion, white peers exhibited low cultural competency, and were especially lacking cultural desire and humility (Campina-Bacote, 2002; Pope et al., 2019; Tervalon \& Murray-García, 1998). This experience was frustrating and made her wonder if she really belonged at the PWI.

Valerie also noted how white peers lacked an eagerness and desire to learn about those different from themselves. She compared her own cultural competency (i.e., humility, desire; Campina-Bacote, 2002; Pope et al., 2019; Tervalon \& MurrayGarcía, 1998) to that of her white peers and explained how the disparity related to her sense of belonging:

My sense of belonging [connects to me] trying to like be open and conversational with people ... so it's just more of a helpful community ... Personally, I don't really like people who aren't willing to try to get to know somebody else. That is like a big pet peeve of mine. . . Even though I get along with people of different races now, I feel that there's still people....in my classes who won't talk to anybody of a different race. So, I felt like if there was more events or forums, or anything or multicultural events, then I feel that people would be like: "Oh, let me go to that." And they would feel more comfortable to talk to different people of different races. Not only for whites talking to people of different races, but also people of color talking to the majority of the people, like whites and everything. I felt that they would feel more comfortable if they knew how to approach [people who are different from themselves].

Literature notes the importance of a sense of connection to the development of belonging (Strayhorn, 2012; Vaccaro \& Newman, 2017). However, Valerie takes this notion further by describing how belonging includes being open to others, having cultural competency (i.e., cultural skill, humility, desire), and creating a sense of 
Journal Committed to Social Change on Race and Ethnicity | Volume 5, Issue 2 | 2019

community with diverse peers (Camphina-Bacote, 2002; Pope et al., 2019; Tervalon \& Murray-García, 1998).

"You feel more comfortable being with the group"

Despite experiences that diminished their sense of belonging, participants drew upon their cultural competency—especially humility and desire-(Camphina Bacote, 2002; Pope et al., 2019; Tervalon \& Murray-García, 1998) to thrive at the PWI by becoming involved in student organizations and programs (i.e., counterspaces) designed for minoritized populations. Students like Camilla explained why counterspaces (campus cultural organizations, multicultural groups, diversity centers) were important to her sense of belonging:

There's always going to be people who are unaccepting, I think that's a given on any campus ... And I would say that the best thing you can do ... is to get involved with something specific to your interests ... or people that you can talk to, then you have a community here.

Destiny also noted that merely knowing multicultural groups and organizations existed on campus increased her sense of belonging. She stated, "I would say I do feel accepted just because there are like groups made for minorities."

In campus counterspaces, participants connected with peers who understood what it was like to be the "only one." Valerie described a Women of Color leadership group:

I feel like when I'm with my organization I feel like I'm not the only one of color. I feel like there's other people who are going through the same thing as me. They probably felt the same way I felt at some point in time when they came to college. So, that kind of helps me out [with belonging].

In contrast to the previous finding that feeling like the "only one" inhibited belonging, participation in campus counterspaces for Women of Color afforded connection, 
Journal Committed to Social Change on Race and Ethnicity | Volume 5, Issue 2 | 2019

community and fostered belonging. Hoa described Asian campus counterspaces (specifically multicultural groups) as places to connect and foster belonging in the presence of similar others:

[When you get to campus], you form a group. You feel more comfortable being with the group. It's just the way I feel . . . Because they are Asian they have kind of the same experience, I expect. So, they have same experiences they go through.

Similarly, Lizette shared: "I joined... a multicultural dance [group where I feel like I belong] because I have different, Cape Verdean, African, Spanish [heritage]. So, I'm still in that [organization] now . . . That's why I don't feel that left out." In sum, participants found refuge (Vaccaro \& Camba-Kelsay, 2016) in counterspaces where they developed authentic connections (Vaccaro \& Newman, 2016) with others who were also trying to navigate a PWI where they were feeling "left out" and surrounded by culturally incompetent peers.

The power of counterspaces to contribute to students' sense of belonging, however, was more complex than merely offering a space where Women of Color found connection and community. As documented in prior writings, through multicultural campus organizations, participants can increase their knowledge of campus and social networks (Vaccaro \& Camba-Kelsay, 2016), and also foster their cultural competency. Kendra shared, "it connects you to so many other things on this campus that I wouldn't have known about." Campus counterspaces also increased women's confidence to successfully navigate subtle and overt exclusion in any environment-including the PWI. Valerie described how a campus group for Women of Color reduced her feelings of minoritization and fostered belonging: 
Journal Committed to Social Change on Race and Ethnicity | Volume 5, Issue 2 | 2019

I feel like by being in the multicultural organization ... that helped me like get a better understanding that people will always watch you-especially if you are a minority ... So, I feel like in a way that helps me out being in an organization ... It gives me a better understanding of everything, like life, like how to deal with certain situations ... Joining certain organizations ... . was important to me because I felt like that's where I belonged. That's where I felt comfortable, the most comfortable. And, now like towards the end of the semester, I'm starting to feel like I could feel comfortable wherever. Because now I'm starting to meet different friends of different races ... At first, I really just felt like I belonged with my organizations, my friends, and family members ... I felt that by talking to people of different races, different ages, and stuff like that, it helps me develop a better understanding of how the university is and how people interact with each other.

Finding comfort and belonging in multicultural campus organizations initially fostered Valerie's sense of interpersonal belonging. As the year progressed, she gained the confidence via counterspace interactions to draw upon her cultural competency skills (Camphina-Bacote, 2002; Pope et al., 2019; Sue, 2001; Tervalon \& Murray-García, 1998) and develop relationships with white peers. Counterspaces helped participants like Valerie learn to navigate university structures and develop not only interpersonal, but also what Vaccaro and Newman (2017) described as institutional-level belonging. In her quest to find community and a sense of belonging, Destiny attended information sessions for campus sororities. Destiny ultimately sought involvement in a multicultural sorority so that she could continue to foster her passion for learning about other cultures. She shared:

I wanted to be in a multicultural sorority because I don't want to be that one little Black girl that's like, "oh, look at the one little Black girl in a whole sorority full of white people." Like, I don't want to be that. I want to be involved where there's white people, Black people, Spanish people, Indian people, Irish people. I want a broad experience of people...So, why not be in a multicultural sorority where you can hear different stories, different backgrounds, different types of things, [and] be involved. 
Journal Committed to Social Change on Race and Ethnicity | Volume 5, Issue 2 | 2019

Although Women of Color, like Destiny, may have initially joined multicultural organizations to find a sense of belonging with similar others, counterspaces allowed participants to satisfy their cultural desires (Camphina-Bacote, 2002), foster cultural humility (Pope et al., 2019; Tervalon \& Murray-García, 1998), and increase their overall cultural competency (Camphina-Bacote, 2002; Pope et al., 2019; Sue, 2001; Tervalon \& Murray-García, 1998).

Finally, campus counterspaces also afforded participants a vehicle for campus diversity leadership. Women of Color sometimes felt a responsibility to serve as campus leaders who taught peers how to be more culturally competent. For instance, Kendra explained how involvement in the [Ethnic Name] Student Organization:

makes me want to teach people more about [my ethnic background] on this campus. It motivates me, too. After like being in [the Women of Color association] and [ethnic student group] I saw that I could be a leader, not just there, but in the classroom ... They motivate me in different ways.

Similarly, Valerie enacted culturally competent leadership (i.e., social justice advocacy; Pope et al. 219) through multicultural organizations. There, she collaborated with students from various racial backgrounds to teach topics related to racial justice and inclusion. She shared:

I get to work with people who are of a different color ... who work for a good cause. So, I feel like I belong, because we also do stuff for the university. I feel like I am helping out at my school, which brings like a high joy to me.

In sum, multicultural counterspaces fostered students' sense of belonging and cultural competency. Counterspaces also served as leadership springboards where students could put their cultural competency into action by encouraging competency development in others. 
Journal Committed to Social Change on Race and Ethnicity | Volume 5, Issue 2 | 2019

\section{Discussion and Implications}

This study documented connections among cultural competency, unmet expectations, compositional and structural diversity, campus counterspaces and the development of a sense of belonging for Women of Color. Our participants felt minoritized when they transitioned from diverse high school and home communities to the PWI. Their sense of belonging was diminished by the lack of compositional, structural, and interactional diversity—despite the university's espoused value of diversity. Belonging was also influenced by the perceived discrepancy between their relatively strong levels of cultural competency and low levels displayed by white peers.

Although our participants did not necessarily use the term cultural competency, they frequently referenced components that are common to all cultural competency models such as awareness, knowledge, and skills (Camphina-Bacote, 2002; Sue, 2001; Pope et al., 2019). Student narratives also drew our attention to unique facets of various cultural competency models such as: desire and encounters (Camphina-Bacote), cultural humility (Pope et al., 2019; Tervalon \& Murray-Garcia, 1998), and social justice advocacy and leadership (Pope et al., 2019). These findings suggest that no single definition of cultural competency may be effective when working with Women of Color in contemporary collegiate settings. Our work also offers an important reminder to scholars to be explicit when writing about their use of complex and evolving concepts (e.g., cultural competency) as analytic tools.

Our study highlights that a sense of belonging has a context-bound history. Students had a stronger sense of belonging in high school and community settings where there was greater cultural/ethnic/racial diversity. With few exceptions (Locks et 
Journal Committed to Social Change on Race and Ethnicity | Volume 5, Issue 2 | 2019

al., 2008; Means \& Pyne, 2017), pre-collegiate experiences and expectations are typically not included in the study of collegiate belonging. Quotes from our participants draw attention to the importance of contrasting contexts over time. Our findings align with Harper's (2013) definition of minoritized, emphasizing the social construction of this term and the contextual nature of being minoritized. Participants did not necessarily feel "minoritized" in diverse community and high school settings where they were surrounded by culturally competent people from diverse racial/ethnic/cultural backgrounds. As Valerie noted, in high school the "minorities were the majority" so she did not feel minoritized. By contrast, the predominately white university made her feel like she "was in a different country" and thus, "felt like I was a minority." Our findings contrast with Means and Pyne (2017) who found low income, first generation Students of Color expected to be minoritized in PWIs. Our participants arrived at the PWI with expectations of meeting, and interacting with, diverse peers. Their narratives illustrate that racially diverse high school and community contexts may play a larger role in the development of collegiate belonging than prior studies suggest.

Participants came to the university with expectations that their cultural awareness would be valued, and that the college experience would expand their cultural competency. Universities, like this one, often espouse the value of diversity via websites, admission viewbooks, orientation tours, and diversity events. However, students experienced a disconnect between these expectations and campus realities such as lack of compositional diversity. Our findings align with Harper and Hurtado (2007, p. 16) who found Students of Color described "frustration with the incongruence of espoused and enacted institutional values concerning diversity" which led to negative 
Journal Committed to Social Change on Race and Ethnicity | Volume 5, Issue 2 | 2019

perceptions of the campus racial climate. In our study, similar frustrations influenced belonging.

Absence of compositional diversity at the PWI seemed to perpetuate another belonging inhibitor-which was the lack of cultural competency of white peers. Participant narratives point to various components of cultural competency such as awareness, knowledge, skills, desire, encounters, and humility that were lacking in their white counterparts (Camphina-Bacote, 2002; Pope et al., 2019; Sue, 2001; Tervalon \& Murray-García, 1998). For instance, they described "ignorant" (Kendra) white peers who were disinterested or resistant to learning about diversity through programs meant to address structural diversity. This study reinforces prior research that suggests negative interactions with white peers inhibits the development of belonging for Students of Color (Locks et al., 2008; Maramba \& Museus, 2012/13; Nuñez, 2009). Our findings delve deeper into these negative interactions to suggest that living and learning with white peers who exuded little cultural awareness, knowledge, skills, humility, desire or prior encounters (Camphina-Bacote, 2002; Pope et al., 2019; Sue, 2001; Tervalon \& MurrayGarcía, 1998) eroded participants' sense of belonging.

When faced with culturally incompetent or indifferent white peers and a lack of campus diversity, Women of Color sought campus counterspaces. These campus spaces helped women feel like they were not the "only one," garner a sense of community, and develop leadership skills (Pérez Huber \& Cueva, 2012; Vaccaro \& Camba-Kelsay, 2016; Yosso et al., 2009). Participants also felt a sense of belonging when surrounded by racially and culturally diverse peers-even if peers did not share their exact cultural identities. This reinforces the importance of not only increasing 
Journal Committed to Social Change on Race and Ethnicity | Volume 5, Issue 2 | 2019

compositional diversity, but also providing intentionally structured and facilitated opportunities for intercultural dialogues (Gurin et al., 2002; Locks et al., 2008). Despite factors that may have undermined their sense of belonging, students described phenomena that helped them feel comfortable and connected. Participants' cultural competency functioned as an asset that enabled them to navigate the PWI and develop belonging in spite of marginalization. Women of Color exuded pride in their cultural competency, expressing confidence that this competence was of great value.

To document effectiveness, universities are obligated to report evidence regarding an array of student outcomes (Eaton, 2015). However, schools rarely measure cultural competency. Moreover, Harper and Hurtado (2007) argued higher education institutions almost never collect rich qualitative data about campus racial climates and experiences. If institutions did engage in this type of assessment, they might find evidence that Women of Color possess advanced levels of cultural competency as compared to white peers. That data could be used to design curricular and co-curricular initiatives that meet students where they are-including more advanced competency-building learning opportunities for Women of Color. All students should have an opportunity to scaffold learning toward increased cultural competency. Providing only basic diversity education may advance the knowledge of some students (e.g., whites), but could be unchallenging and a disservice for Women of Color. Higher education professionals should recognize cultural competency (Camphina-Bacote, 2002; Pope et al., 2004, 2019; Sue, 2001; Tervalon \& MurrayGarcía, 1998) as an asset when selecting students for recognition (e.g., awards, scholarships) and when recruiting student leaders (e.g., resident assistants, orientation 
Journal Committed to Social Change on Race and Ethnicity | Volume 5, Issue 2 | 2019

leaders, tutors). Such recognition is especially important when hiring student leaders for roles that require cultural competency for success. However, recognizing cultural competency strengths can also lead to tokenizing Women of Color and using them to bear the responsibility of inclusion work on campus. That is not our intention. Instead, we aim to flip the dominant script of portraying students of color through a deficit belonging lens and instead to recognize their strengths related to cultural competency (Camphia-Bacote, 2002; Pope et al., 2019; Sue, 2001; Tervalon \& Murray-García, 1998).

Studies that noted that Students of Color report lower levels of belonging than white peers (Hurtado \& Carter, 1997; Johnson et al., 2007; Strayhorn, 2008) are sometimes interpreted to suggest that Students of Color can increase belonging by better adapting to their predominately white university environment. However, as we listened to our participants, we heard a different message. Women of Color detected a degree of hypocrisy between the university's public messages and their actions. However, they found pathways to belonging through interpersonal involvement in counterspaces that recognized and advanced their cultural competence. Like our participants, we contend that universities must engage in institutional transformation (Harper \& Hurtado, 2007) and make structural efforts to foster both interpersonal and institutional-level belonging (Vaccaro \& Newman, 2017) by supporting multicultural programs, fostering campus counterspaces, increasing enrollment of Students of Color, and recruiting faculty and staff of color. As our participants noted, these initiatives can foster cultural competency in all students-especially white students who may arrive on campus with less cultural competency because they have had fewer pre-collegiate 
Journal Committed to Social Change on Race and Ethnicity | Volume 5, Issue 2 | 2019

cultural encounters (Camphina-Bacote, 2002). Participant narratives suggest that increased diversity enrollments and more cross-racial/ethnic interactions might have increased their belonging only if these efforts coincided with increased cultural competency—especially humility (Pope et al., 2019; Tervalon \& Murray-Garcia, 1998) and desire (Camphina-Bacote, 2002) of white peers. This finding aligns with higher education writings suggesting that increased diversity enrollments alone are insufficient for improving campus climates (Harper \& Hurtado, 2007; Hurtado et al., 1998; Milem et al., 2005, Williams, 2013) and that interracial interactions must be frequent and positive to increase belonging (Locks et al., 2008). Diversifying a student body (i.e., compositional diversity) must be one—but not the only—aspect of comprehensive structural diversity efforts to improve campus climate for Students of Color.

Higher education scholarship has underscored the importance of interpersonal interactions among different racial groups on campus for enhanced educational outcomes such as intellectual engagement and increased self-assessed academic skills (Gurin et al., 2002). Our findings suggest that interactions with less culturally competent peers may lead to elementary-level cultural dialogues—because white students "just don't know" and are "ignorant", as Kendra noted in her interview. Interactional diversity experiences (Gurin et al., 2002; Locks et al., 2008; Vaccaro \& Camba-Kelsay, 2016) may actually be harmful if Women of Color are constantly expected to interact with, and educate, culturally incompetent white peers, especially those who do not appear to be open to culturally diverse views or who do not seek opportunities to learn (i.e. cultural desire, humility). Efforts to educate others can feel like a burden that deflects time and resources away from a student's other educational endeavors. Such burdens have been 
Journal Committed to Social Change on Race and Ethnicity | Volume 5, Issue 2 | 2019

described for faculty/staff of color who experience a cultural tax when expected to support Students of Color and represent diversity (e.g., committees, recruitment) in addition to their regular job duties (Joseph \& Hirshfield, 2011). Other research noted how social justice activist efforts of graduate students benefit post-secondary institutions, but can feel like a form of unpaid labor for those students (Linder et al., 2019). Although our participants expressed a willingness to do some peer education via campus leadership, creating a culturally competent student body is the responsibility of institutions, not Students of Color. We contend that it is inappropriate, and unethical, to expect women of color to perform this kind of labor (Linder et al., 2019) and incur a cultural tax on their education.

As Camilla noted, "There's always going to be people who are unaccepting" so counterspaces are important getaways and places of refuge for Women of Color (Vaccaro \& Camba-Kelsay, 2016; Yosso et al., 2009). In an era when multicultural centers report receiving "barely" any or "lukewarm" support from administrators and faculty (Stewart \& Bridges, 2011, p. 54), our findings reinforce the need for these kinds of campus counterspaces. Educators must find ways to shield multicultural programs from cuts and service reductions. Higher educators must also educate students, colleagues, and the public about why these programs are important counterspaces where Women of Color find support, increase cultural competency, foster leadership, and develop a sense of belonging.

\section{Conclusion}

If belonging is a basic human need (Strayhorn, 2012) associated with academic success (Freeman et al., 2007; Strayhorn, 2008, 2012), persistence (Hausmann et al., 
Journal Committed to Social Change on Race and Ethnicity | Volume 5, Issue 2 | 2019

2007; Hoffman et al., 2002/2003), and psychological adjustment (Pittman \& Richmond, 2008), universities have an obligation to foster it in all students. Our findings show both increased compositional and structural diversity, meeting students' diversity expectations via enactment of espoused diversity values, providing access to counterspaces, offering structured intergroup dialogue, and fostering cultural competency can work in tandem to positively shape the complex belonging trajectories of Women of Color at PWIs.

\section{References}

Blaney, J. M., \& Stout, J. G. (2017). Examining the relationship between introductory computing course experiences, self-efficacy, and belonging among firstgeneration college women. In Proceedings of the 2017 ACM SIGCSE Technical Symposium, 69-74. doi: 10.1145/3017680.3017751

Camphina-Bacote, J. (2002). The process of cultural competence in the delivery of healthcare services: A model of care. Journal of Transcultural Nursing, 13(3), 181-184. doi: 10.1177/10459602013003003

Charmaz, K. (2014). Constructing grounded theory: A practical guide through qualitative analysis (2nd ed.). Los Angeles, CA: Sage.

Eaton, J. S. (2015). An overview of U.S. accreditation. Washington, D.C.: Council for Higher Education Accreditation. Retrieved from: https://www.chea.org/sites/default/files/othercontent/Overview\%20of\%20US\%20Accreditation\%202015.pdf

Freeman, T. M., Anderman, L. H., \& Jensen, J. M. (2007). Sense of belonging in college freshmen at the classroom and campus levels. The Journal of Experimental Education, 75(3), 203-220. doi: 10.3200/jexe.75.3.203-220 
Journal Committed to Social Change on Race and Ethnicity | Volume 5, Issue 2 | 2019

Gurin, P., Dey, E. L., Hurtado, S., \& Gurin, G. (2002). Diversity and higher education: Theory and impact on educational outcomes. Harvard Educational Review, 72(3), 330-366. doi: 10.17763/haer.72.3.01151786u134n051

Harper, S. R. (2013). Am I my brother's teacher? Black undergraduates, racial socialization, and peer pedagogies in predominantly white postsecondary contexts. Review of Research in Education, 37(1), 183-211. doi: 10.3102/0091732X12471300

Harper, S. R., \& Hurtado, S. (2007). Nine themes in campus racial climates and implications for institutional transformation. In S. Harper \& L. D. Patton (Eds.). Responding to the realities of race on campus. New Directions for Student Services (120), pp. 7-24. San Francisco, CA: Wiley. doi: 10.1002/ss.254

Hausmann, L. R. M, Schofield, J. W., \& Woods, R. L. (2007). Sense of belonging as a predictor of intentions to persist among African American and white first-year college students. Research in Higher Education, 48(7), 803-839. doi: 10.1007/s11162-007-9052-9

Hoffman, M., Richmond, J., Morrow, J., \& Salomone, K. (2002/2003). Investigating "sense of belonging" in first-year college students. Journal of College Student Retention, 4(3), 227-256. doi: 10.2190/DRYC-CXQ9-JQ8V-HT4V

Hurtado, S., \& Carter, D.F. (1997). Effects of college transition and perceptions of the campus racial climate on Latino students' sense of belonging. Sociology of Education, 70(4), 324-345. doi: 10.2307/2673270

Hurtado, S., Clayton-Pedersen, A. R., Allen, W. R., \& Milem, J. F. (1998). Enhancing campus climates for racial/ethnic diversity: Educational policy and practice. The Review of Higher Education, 21(3), 279-302. doi: 10.1353/rhe.1998.0003

Johnson, D. R., Soldner, M., Leonard, J. B., Alvarez, P., Inkelas, K. K., Rowan-Kenyon, H., \& Longerberm, S. D. (2007). Examining sense of belonging among first-year undergraduates from different racial/ethnic groups. Journal of College Student Development, 48(5), 525-542. doi: 10.1353/csd.2007.0054

Jones, S. R., Torres, V., \& Arminio, J. (2014). Negotiating the complexities of qualitative research in higher education: Fundamental elements and issues (2nd ed.). New York, NY: Routledge. doi: 10.4324/9780203123836 
Journal Committed to Social Change on Race and Ethnicity | Volume 5, Issue 2 | 2019

Joseph, T. D., \& Hirshfield, L. E. (2011). 'Why don't you get somebody new to do it?' Race and cultural taxation in the academy. Ethnic and Racial Studies, 34(1), 121-141. doi: 10.1080/01419870.2010.496489

Linder, C., Quaye, S. J., Lange, A. C., Roberts, R. E., Lacy, M. C., \& Okello, W. K. (2019). "A student should have the privilege of just being a student": Student activism as labor. The Review of Higher Education, 42(5), 37-62. doi: 10.1353/rhe.2019.0044

Locks, A. M., Hurtado, S., Bowman, N. A., \& Oseguera, L. (2008). Extending notions of campus climate and diversity to students' transition to college. Review of Higher Education, 31(3), 257-285. doi: 10.1353/rhe.2008.0011

Maramba, D. C., \& Museus, S. D. (2012/13). Examining the effects of campus climate, ethnic group cohesion, and cross-cultural interaction on Filipino American students' sense of belonging in college. Journal of College Student Retention: Research, Theory and Practice, 14(4), 495-522. doi: 10.2190/cs.14.4.d

Means, D. R. \& Pyne, K. B. (2017). Finding my way: Perceptions of institutional support and belonging in low-income, first-generation, first-year college students. Journal of College Student Development, 58(6), 907-924. doi: 10.1353/csd.2017.0071

Milem, J. F., Chang, M. J., \& antonio, A. L. (2005). Making diversity work on campus: A research-based perspective. Washington, DC: Association American Colleges and Universities. Retrieved from: https://www.aacu.org/sites/default/files/files/mei/MakingDiversityWork.pdf

Mohanty, C. T. (1991). Under western eyes: Feminist scholarship and colonial discourses. In C.T. Mohanty, A. Russo, \& L. Torres (Eds.), Third world women and the politics of feminism (pp. 51-80). Bloomington, IN: Indiana University Press.

Nuñez, A-M. (2009). A critical paradox? Predictors of Latino students' sense of belonging in college. Journal of Diversity in Higher Education, 2(1), 46-61. doi:10.1037/a0014099

Pérez Huber, L. \& Cueva, B. M. (2012). Chicana/Latina testimonios on effects and responses to microaggressions. Equity and Excellence in Education, 45(3), 392410. doi: 10.1080/10665684.2012.698193 
Journal Committed to Social Change on Race and Ethnicity | Volume 5, Issue 2 | 2019

Pittman, L.D. \& Richmond, A. (2008). University belonging, friendship quality, and psychological adjustment during the transition to college. Journal of Experimental Education, 76, 343-361. doi: 10.3200/jexe.76.4.343-362

Pope, R. L., \& Reynolds, A. L. (1997). Student affairs core competencies: Integrating multicultural awareness, knowledge, and skills. Journal of College Student Development, 38(3), 266-277.

Pope, R. L., Reynolds, A. L., \& Mueller, J. A. (2004). Multicultural competence in student affairs. Jossey-Bass.

Pope, R. L., Reynolds, A. L., \& Mueller, J. A. (2019). Multicultural competence in student affairs. San Francisco, CA: Jossey-Bass.

Stebleton, M. J., Soria, K. M., \& Huesman, R. L. (2014). First-generation students' sense of belonging, mental health, and use of counseling services at public research universities. Journal of College Counseling, 17(1), 6-20. doi: 10.1002/j.2161-1882.2014.00044.x

Stephens, N. M., Fryberg, S. A., Markus, H. R., \& Johnson, C. S. (2012). Unseen disadvantage: How American universities' focus on independence undermines the academic performance of first generation college students. Journal of Personality and Social Psychology, 12(6), 1178-1197. doi: 10.1037/a0027143

Stewart, D. L., \& Bridges, B. (2011). A demographic profile of multicultural student services. In D. L. Stewart (Ed.). Multicultural student services on campus: Building bridges, re-visioning community, (pp. 38-62). Sterling, VA: Stylus.

Stewart, D. L., \& Bridges, B. (2011). A demographic profile of multicultural student services. In D. L. Stewart (Ed.). Multicultural student services on campus: Building bridges, re-visioning community, (pp. 38-62). Sterling, VA: Stylus.

Strayhorn, T. L. (2008). Sentido de pertenencia: A hierarchical analysis predicting sense of belonging among Latino college students. Journal of Hispanic Higher Education, 7(4), 301-320. doi: 10.1177/1538192708320474

Strayhorn, T. L. (2012). College students' sense of belonging: A key to educational success for all students. New York, NY: Routledge. doi: $10.4324 / 9780203118924$ 
Journal Committed to Social Change on Race and Ethnicity | Volume 5, Issue 2 | 2019

Sue, D. W. (2001). Multidimensional facets of cultural competence. The Counseling Psychologist, 29(6), 790-821. doi: 10.1177/0011000001296002

Tervalon, M., \& Murray-García, J. (1998). Cultural humility versus cultural competence: A critical distinction in defining physician training outcomes in multicultural education. Journal of Health Care for the Poor and Undeserved, 9(2), 117-125. doi:10.1353/hpu.2010.0233

Vaccaro, A., \& Camba-Kelsay, M. J. (2016). Centering women of color in academic counterspaces: A critical race analysis of teaching, learning, and classroom dynamics. Lanham, MD: Lexington Books.

Vaccaro, A. \& Newman, B. M. (2016). The development of a sense of belonging for privileged and minoritized students: An emerging model. Journal of College Student Development, 57(8), 925-942. doi: 10.1353/csd.2016.0091

Vaccaro, A., \& Newman, B. M. (2017). Belonging through the eyes of first-year LGBP students: A multi-layered analysis. Journal of Student Affairs Research and Practice, 54(2), 137-149. doi:10.1080/19496591.2016.1211533

Williams, D. A. (2013). Strategic diversity leadership: Activating change and transformation in higher education. Sterling, VA: Stylus Publishing.

Williams, D. A., Berger, J. B., \& McClendon, S. A. (2005). Toward a model of inclusive excellence and change in postsecondary institutions. Washington, DC: Association of American Colleges and Universities.

Yosso, T., Smith, W., Ceja, M., \& Solórzano, D. (2009). Critical race theory, racial microaggressions, and campus climate for Latina/o undergraduates. Harvard Educational Review, 79(4) 659. doi: 10.17763/haer.79.4.m6867014157m707I 